\title{
PENGARUH KUALITAS ARGUMEN DAN KREDIBILITAS SUMBER TERHADAP NIAT PEMBELIAN YANG DIMEDIASI OLEH KEGUNAAN INFORMASI
}

\author{
Ni Luh Putu Ayu Yoceilla Waisnawa1 \\ Ni Made Rastini ${ }^{2}$ \\ ${ }^{1,2}$ Fakultas Ekonomi dan Bisnis Universitas Udayana (Unud), Bali, Indonesia \\ email: shellawaisnawa@gmail.com
}

\begin{abstract}
ABSTRAK
Niat pembelian merupakan rencana yang didasarkan informasi dan pengetahuan calon konsumen mengenai sebuah produk atau layanan tertentu. Penelitian ini bertujuan untuk menjelaskan pengaruh kualitas argumen dan kredibilitas sumber terhadap niat pembelian yang dimediasi oleh kegunaan informasi pada lipstick Wardah di Kota Denpasar. Penelitian ini dilakukan di Kota Denpasar, Bali dengan menggunakan teknik non probability sampling dengan purposive sampling, mengambil responden sebanyak 100 orang melalui kuesioner. Teknik analisis data yang digunakan adalah dengan menggunakan statistik deskriptif, analisis jalur, dan uji sobel. Berdasarkan hasil analisis ditemukan kualitas argumen dan kredibilitas sumber berpengaruh positif dan signifikan terhadap kegunaan informasi dan niat pembelian. Hal ini menunjukkan bahwa semakin baik kualitas konten dan semakin kredibel sumber yang digunakan, maka akan semakin berguna informasi yang akan disampaikan sehingga akan semakin tinggi niat pembelian dari calon konsumen. Kegunaan informasi memediasi secara positif dan signifikan hubungan kualitas argumen dan kredibilitas sumber terhadap niat pembelian. Hasil analisis yang diperoleh dari kedua teknik analisis menunjukkan bahwa secara positif dan signifikan kegunaan informasi mampu memediasi hubungan kualitas argumen dan kredibilitas sumber terhadap niat pembelian pada lipstick Wardah di Kota Denpasar.
\end{abstract}

Kata kunci: kegunaan informasi, kredibilitas sumber, kualitas argumen, niat pembelian

\begin{abstract}
Purchase intention is information and knowledge of prospective consumers about a particular product or service. This study aims to explain the effect of argument quality and source credibility on purchase intentions mediated by information usefulness on Wardah lipsticks in Denpasar. This research was conducted in Denpasar, Bali using non probability sampling techniques with purposive sampling, taking respondents as many as 100 people through questionnaires. Data analysis technique used descriptive statistics, path analysis, and sobel tests. Based on the results of the analysis found the argument quality and the source credibility has a positive and significant effect on the information usefulness and purchase intentions. This shows that the better the quality of the content and the more credible the sources, the more useful the information will be delivered so that the higher the purchase intention of the prospective consumer. The information usefulness mediates positively and significantly the relationship between the argument quality and the source credibility against purchase intentions. The results of the analysis obtained from the two analytical techniques show that positively and significantly the information usefulness is able to mediate the relationship between the argument quality and the source credibility of purchase intentions on Wardah lipsticks in Denpasar.

Keywords: information usefulness, source credibility, argument quality, purchase intentions
\end{abstract}




\section{PENDAHULUAN}

Semakin mudahnya akses internet di Indonesia, semakin memudahkan masyarakat dalam menambah pengetahuan, melakukan transaksi, mengakses data, sebagai media komunikasi dan media persuasi. Populasi pengguna internet di Indonesia pada hasil survey yang dilakukan oleh APJII (Asosiasi Penyelenggara Jasa Internet Indonesia) dari tahun 2008 sampai dengan 2018 terus mengalami peningkatan, hasil survey tersebut dapat dilihat pada Gambar 1. yang menunjukkan peningkatan pertumbuhan pengguna internet di Indonesia tahun 2008-2018.

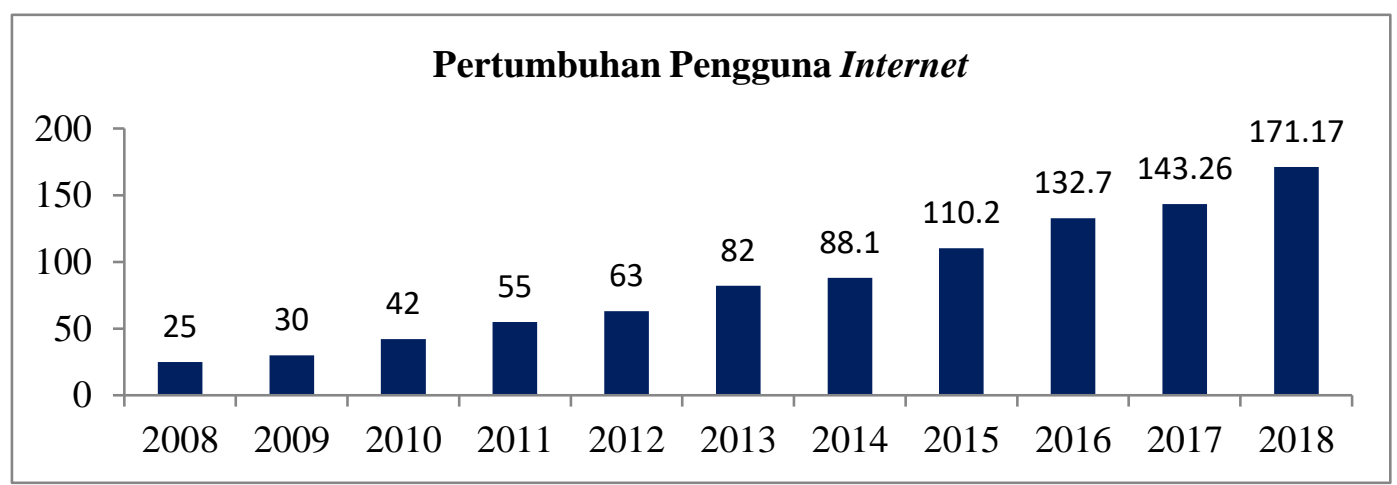

Gambar 1. Pertumbuhan Pengguna Internet di Indonesia Tahun 2008-2018

Sumber: Asosiasi Penyelenggara Jasa Internet Indonesia, 2019

Selain itu di Bali, terutama di Kota Denpasar sebagai Ibu Kota di Provinsi Bali dan merupakan kota dengan akses internet tertinggi, sebanyak 68 persen masyarakatnya telah mengakses internet (Kurnia, 2019). Kota Denpasar juga telah ditetapkan sebagai kota besar dengan skor 61,70 dalam Indeks Kota Cerdas Indonesia (IKCI) pada tahun 2018 berdasarkan indikator lingkungan, mobilitas, ekonomi, masyarakat, pemerintahan dan kualitas hidup (Kompasiana, 2019). Pertumbuhan internet di Indonesia dan di Bali kini kian meningkat sehingga menyebabkan digitalisasi informasi menjadi sangat mudah. Digitalisasi telah menciptakan peluang bagi perusahaan dengan banyaknya teknologi baru yang muncul, banyak saluran yang lebih murah dan lebih baru untuk menjangkau konsumen secara luas (Kotler et al., 2017:12).

YouTube merupakan salah satu media sosial yang sering digunakan saat ini. Berdasarkan data dari Asosiasi Penyelenggara Jasa Internet Indonesia tahun 2018, YouTube merupakan konten internet (media sosial) ketiga yang paling sering dikunjungi (15,1 persen), sebelum YouTube terdapat Instagram (17,8 persen) dan Facebook (50,7 persen). Salah satu bentuk konten dalam YouTube adalah review videos. Review mengacu pada ulasan yang ditulis oleh pengguna atau konsumen pada sebuah produk yang berdasarkan pada pengalaman pengguna produk tersebut. Review oleh konsumen digunakan sebagai dasar untuk pencarian informasi konsumen dan memiliki dampak pada perilaku pembelian konsumen (Almana dan Mirza, 2013)

Data statistik yang dilansir oleh Statista yang dirilis pada November 2018 secara global, menyatakan bahwa terdapat kenaikan yang signifikan dari tahun 
2006-2018 terkait konten kecantikan di YouTube. Pada tahun 2006 konten kecantikan menghasilkan 0,13 miliar tampilan dan hingga 2018 menghasilkan lebih dari 169 miliar tampilan. Pada saat ini konten kecantikan yang populer adalah video tutorial, video DIY (Do It Yourself), reviews, haul videos, dan video yang diproduksi oleh vloggers kecantikan. Data disajikan pada Gambar 2.

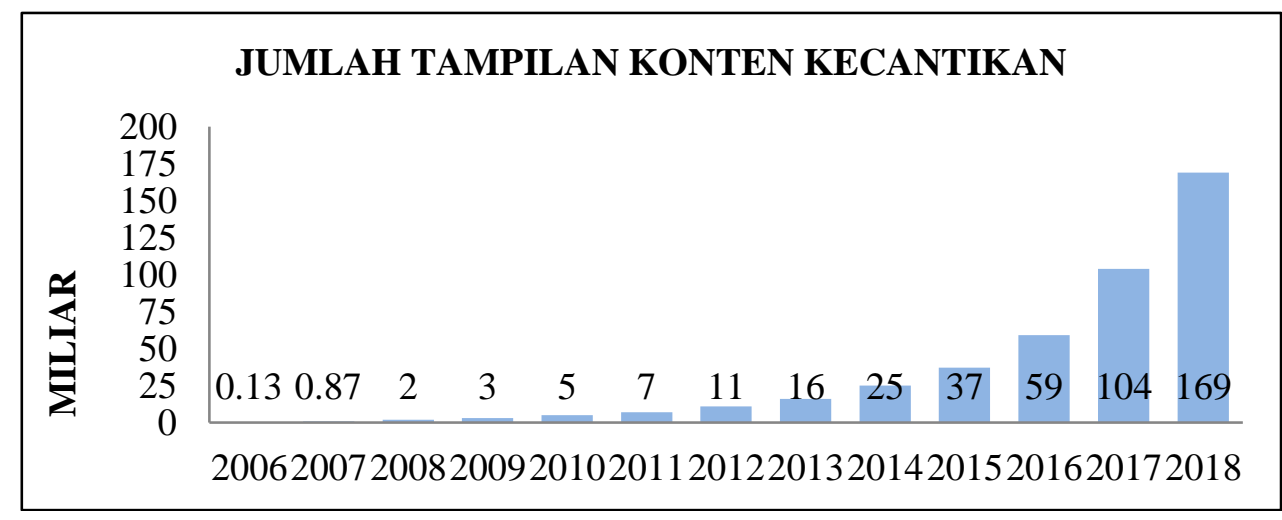

\section{Gambar 2. Jumlah Tampilan Konten Kecantikan di YouTube Tahun 2006- 2018}

Sumber : www.statista.com, 2018

Sejalan dengan jumlah tampilan konten, di industri kosmetik nasional mencatatkan peningkatan sebesar 20 persen atau empat kali lipat dari pertumbuhan ekonomi nasional pada tahun 2017. Kenaikan ini didukung oleh permintaan terhadap produk-produk kecantikan yang semakin besar di pasar domestik dan ekspor seiring dengan tumbuhnya tren kecantikan di masyarakat yang mulai memperhatikan produk perawatan wajah dan tubuh. Pada tahun 2018, industri kosmetik di dalam negeri telah bertambah sebanyak 153 perusahaan dari tahun 2017 dan perusahaan kecantikan telah mencapai lebih dari 760 perusahaan di Indonesia dengan pembagian sebanyak 95 persen merupakan industri kecil dan menengah (IKM) dan sisanya merupakan industri skala besar (Kemenperin.go.id, 2018).

Data pada ZAP Beauty Index yang disajikan pada Tabel 1. menunjukkan bahwa lipstick menjadi produk makeup dengan persentase paling tinggi diantara produk lain yang wajib berada dalam tas para wanita Indonesia, hal ini menunjukkan bahwa lipstick menjadi produk yang paling dibutuhkan daripada produk makeup yang lainnya. Lipstick adalah pewarna bibir berbentuk padat (stik), pensil, palet, krayon dan dikemas dalam botol dengan tekstur cair. Lipstick memiliki tekstur yang bervariasi seperti creamy, satin dan matte (Beauty Journal, 2019). Survei dari ZAP Beauty Index menyatakan bahwa dari sekian banyak brand makeup di Indonesia, untuk produk lipstick, brand Wardah menjadi salah satu brand yang paling diminati. 
Tabel 1.

Produk Makeup yang Dianggap Wajib

\begin{tabular}{lll}
\hline No & Jenis Produk & Persentase (\%) \\
\hline 1 & Lipstick & 66,3 \\
2 & Compact Powder & 36,2 \\
3 & Lipbalm & 26,4 \\
4 & Eyebrow & 22,0 \\
5 & Oil Control Paper & 21,0 \\
\hline
\end{tabular}

Sumber: ZAP Beauty Index, 2018

Wardah sebagai salah satu brand besar di industri kecantikan dan sebagai pelopor dalam menciptakan produk kecantikan bersertifikat halal di Indonesia menjadikan Wardah sebagai brand yang diminati masyarakat. Wardah kini dalam naungan PT. Paragon Technology and Inovation yang telah berdiri sejak 1985 dan didirikan oleh Ibu Dra.Hj.Nurhayati Subakat, Apt. (www.paragoninnovation.com). Berdasarkan laporan Nielsen per September 2018, Wardah adalah merek kosmetik dengan pertumbuhan tertinggi, mencapai 25 persen. Pertumbuhan ini lima kali lebih tinggi dari pertumbuhan ekonomi, bahkan di atas pertumbuhan industri kosmetik yang bergerak di kisaran 7 persen. Wardah memegang market share sekitar 30 persen di pasar makeup nasional. Wardah telah memiliki sekitar 300 jenis produk kosmetik dan skincare dengan kisaran harga mulai Rp 16.000 hingga Rp 667.000 (Bachdar, 2018). Berdasarkan kategori produk lipstick, brand Wardah menempati posisi top brand dari tahun 2015 sampai tahun 2019 dibandingkan dengan kompetitornya pada brand lain dan data disajikan dalam Tabel 2.

Tabel 2.

Data Top Brand Index Produk Lipstick Tahun 2015-2019

\begin{tabular}{llllll}
\hline Tahun & $\mathbf{2 0 1 5}$ & $\mathbf{2 0 1 6}$ & $\mathbf{2 0 1 7}$ & $\mathbf{2 0 1 8}$ & $\mathbf{2 0 1 9}$ \\
Merek & TBI $(\%)$ & TBI $(\%)$ & TBI $(\%)$ & TBI $(\%)$ & TBI $(\%)$ \\
\hline Wardah & 14,9 & 22,3 & 25,0 & 36,2 & 33,4 \\
Revlon & 12,8 & 13,3 & 12,7 & 10,7 & 9,2 \\
Pixy & 11,0 & 9,3 & 9,6 & - & 6,0 \\
Viva & - & 8,9 & 8,8 & 7,6 & 4,5 \\
Oriflame & 7,7 & 6,5 & 5,7 & - & - \\
Sariayu & 7,6 & - & - & 7,2 & - \\
La Tulipe & 7,3 & 5,5 & 5,1 & - & - \\
Maybelline & - & - & - & - & 7,7 \\
Mirabella & - & - & - & 7,5 & - \\
\hline
\end{tabular}

Sumber: www.topbrand.com, 2019

Wardah dapat mencapai posisi tersebut karena memiliki komunikasi pemasaran yang baik yaitu salah satunya dengan menggunakan beauty endorser yang akan memengaruhi calon konsumen sehingga tertarik untuk mencari informasi selanjutnya mengenai lipstick Wardah. Ulasan online positif mengenai tekstur lipstick, formula lipstick, harga, variansi warna dan termasuk produk yang halal juga menjadi faktor lainnya yang mendukung Wardah menjadi top brand.

Niat beli merupakan sikap konsumen yang merasa tertarik terhadap suatu produk maupun jasa yang dirasakan sesuai dengan kebutuhan yang dialami 
konsumen tersebut. Penelitian yang dilakukan oleh Fan dan Miao (2012) menyatakan bahwa perusahaan dapat menyediakan lebih banyak informasi mengenai produk secara online untuk meningkatkan kredibilitas eWOM, penerimaan $e W O M$, dan niat pembelian. Konsumen yang mengadopsi informasi $e W O M$ akan cenderung memiliki niat pembelian pada sebuah produk (Erkan dan Evans, 2016).

Kegunaan informasi yang dirasakan mengacu pada persepsi mengenai pesan dalam eWOM menjadi bermanfaat (Cheung dan Thadani, 2012). Kegunaan informasi memiliki dampak yang kuat dan signifikan terhadap keputusan konsumen dalam mengadopsi informasi di komunitas online (Cheung et al., 2008). Kegunaan informasi dari eWOM kepada seorang individu juga dipengaruhi oleh kualitas dari konten dan kredibilitas sumber (Mishra dan Satish, 2016).

Kredibilitas sumber mengacu pada kemampuan dan motivasi yang dirasakan dari sumber pesan agar memberikan informasi yang akurat dan benar. Sumber informasi yang dapat dipercaya umumnya akan meningkatkan persuasi suatu pesan dan mendorong perubahan sikap individu menjadi lebih cepat (Li dan Zhan, 2011). Berdasarkan penelitian yang dilakukan oleh Martawilaga dan Purwanegara (2016) menyatakan bahwa orang-orang yang memiliki pengalaman di bidang fesyen, memiliki minat dalam bidang fesyen dan ahli dalam fesyen, lalu memberikan informasi kepada audiens akan meningkatkan kepercayaan konsumen yang berujung pada niat pembelian. Penelitian yang dilakukan oleh Soenarno dkk. (2015) pada forum online Kaskus menyatakan bahwa dalam komunitas selalu memberikan informasi dari sumber yang kredibel untuk pembacanya.

Kualitas argumen diartikan sebagai faktor yang dapat menerima informasi berdasarkan penilaian validitas selama pemrosesan sistematis tergantung pada persepsi akan terjadi lebih rendah atau lebih tinggi (Larasati dan Kerti, 2018). Berdasarkan penelitian Cheung et al. (2008) menyatakan bahwa akurasi, relevansi, pemahaman, kelengkapan, mata uang, dinamika, personalisasi dan variasi menjadi ukuran untuk kualitas informasi dalam studi e-commerce. Gaya penulisan ulasan online, keahlian pengulas, dan ketepatan waktu ulasan online adalah faktor yang menentukan adopsi informasi tersampaikan dengan baik (Almana dan Mirza, 2013).

Martawilaga dan Purwanegara (2016), menyatakan bahwa, persepsi manfaat, kredibilitas sumber dan kualitas argumen berpengaruh positif dan signifikan dalam memengaruhi orang yang memiliki anggapan tentang video sebagai informasi yang bermanfaat. Namun Cheung et al. (2008), menyatakan bahwa kredibilitas sumber tidak memainkan peran penting dalam memengaruhi kegunaan informasi. Penelitian yang dilakukan oleh Erkan dan Evans (2016), juga menyatakan bahwa kualitas informasi dari website belanja lebih berpengaruh dibandingkan kualitas informasi dari sosial media (eWOM) terhadap niat pembelian konsumen.

Sa'ait et al. (2016), menyatakan bahwa kualitas argumen dari sebuah review yang meliputi relevansi, aktualitas, keakuratan dan kelengkapan dalam informasi yang dimasukan ke dalam bentuk komunikasi eWOM memiliki hubungan yang positif dengan niat pembelian konsumen. Sedangkan, penelitian yang dilakukan 
oleh Erkan dan Evans (2016), menyatakan bahwa kualitas informasi dari website belanja lebih berpengaruh dibandingkan kualitas informasi dari sosial media (eWOM) terhadap niat pembelian konsumen. Yasinta dan Sulistyawati (2018), menyatakan bahwa semakin tertarik konsumen dengan keahlian dari celebrity endorser, maka akan semakin tinggi niat beli dari pelanggan pada produk kosmetik Wardah. Namun, penelitian yang dilakukan oleh Martawilaga dan Purwanegara (2016), menyatakan bahwa kredibilitas sumber berpengaruh positif tetapi tidak signifikan terhadap niat pembelian.

Berdasarkan research gap dari penelitian-penelitian yang telah dilakukan sebelumnya mengenai variabel kualitas argumen, kredibilitas sumber, kegunaan informasi dan niat pembelian, maka dilakukan analisis pengaruh kualitas argumen dan kredibilitas sumber terhadap niat pembelian konsumen lipstick Wardah yang dimediasi oleh kegunaan informasi.

Tujuan penelitian ini adalah untuk menjelaskan pengaruh kualitas argumen dan kredibilitas sumber terhadap kegunaan informasi pada review lipstick Wardah di YouTube, pengaruh kualitas argumen, kredibilitas sumber dan kegunaan informasi terhadap niat pembelian lipstick Wardah, dan menjelaskan pengaruh kegunaan informasi memediasi antara kualitas argumen dan kredibilitas sumber terhadap niat pembelian lipstick Wardah. Hasil penelitian ini diharapkan menambah referensi baru dan dapat memberikan sumbangan empiris yang berkaitan dengan variabel kualitas argumen, kredibilitas sumber, kegunaan informasi dan niat pembelian serta dapat digunakan perusahaan dan marketer sebagai bahan dalam melakukan strategi pemasaran di era digital saat ini sehingga dapat menciptakan kesadaran konsumen akan suatu produk.

Penelitian yang dilakukan oleh Chen et al. (2014) dan Retnowati (2017) menyatakan bahwa kualitas argumen berpengaruh positif dan signifikan memengaruhi kegunaan informasi. Hal ini memiliki arti bahwa semakin tinggi kualitas argumen dalam sebuah review maka akan semakin berguna informasi yang dirasakan.

$\mathrm{H}_{1}$ : Kualitas argumen berpengaruh positif dan signifikan terhadap kegunaan informasi

Penelitian yang dilakukan oleh Yuniarti (2019) menyatakan bahwa kredibilitas sumber memiliki pengaruh yang signifikan terhadap kegunaan informasi, artinya semakin tinggi kredibilitas dari suatu sumber maka akan lebih berguna pula informasi yang ada. Hal serupa juga disampaikan oleh Chen et al. (2014), menyatakan bahwa kredibilitas sumber memiliki pengaruh positif dan signifikan terhadap kegunaan informasi.

$\mathrm{H}_{2}$ : Kredibilitas sumber berpengaruh positif dan signifikan terhadap kegunaan informasi

Penelitian yang dilakukan oleh Cheung (2014) menyatakan bahwa kegunaan informasi memiliki efek positif dan signifikan terhadap niat beli. Didukung oleh penelitian Cho dan Sagynov (2015), yang menyatakan bahwa kegunaan yang dirasakan dalam lingkungan online memiliki pengaruh yang signifikan secara statistik terhadap perilaku niat berbelanja online pelanggan. Hal ini berarti, semakin berguna informasi yang disampaikan maka akan semakin tinggi niat pembelian yang dirasakan. 
$\mathrm{H}_{3}$ : Kegunaan informasi berpengaruh positif dan signifikan terhadap niat pembelian

Park et al. (2007), menyatakan bahwa kualitas ulasan konsumen secara online berpengaruh positif terhadap niat pembelian konsumen. Ulasan yang logis dan persuasif yang memiliki fakta spesifik tentang produk memiliki efek positif yang kuat pada niat pembelian. Semakin tinggi intensitas (kuat) komunikasi $e W O M$ yang terjadi akan meningkatkan rasa ingin tahu konsumen mengenai hal yang akan dikomunikasikan, sehingga akan menimbulkan minat beli seiring dengan berjalannya waktu (Ardana dan Rastini, 2018).

$\mathrm{H}_{4}$ : Kualitas argumen berpengaruh positif dan signifikan terhadap niat pembelian

Penelitian yang dilakukan oleh Arsinta dan Purnami (2015), menyatakan bahwa endorser memiliki pengaruh yang positif dan signifikan terhadap niat pembelian, hal ini juga didukung oleh penelitian yang dilakukan oleh Husna dan Bayu (2018). Hal ini memiliki arti bahwa semakin tinggi kredibilitasnya maka akan semakin tinggi niat pembeliannya.

$\mathrm{H}_{5}$ : Kredibilitas sumber berpengaruh positif dan signifikan terhadap niat pembelian

Berdasarkan hipotesis yang dipaparkan oleh Cheung dan Thadani (2012), bahwa kualitas informasi pada adopsi eWOM dapat dimediasi oleh kegunaan informasi. Kegunaan informasi dari isi dalam online review sangat bermanfaat karena dapat memberikan informasi yang dibutuhkan konsumen sehingga akan memudahkan konsumen dalam memilih dan mempertimbangkan isi konten dan akan memengaruhi minat beli (Jap dkk., 2018).

$\mathrm{H}_{6}$ : Kegunaan informasi memediasi kualitas argumen sumber terhadap niat pembelian

Berdasarkan penelitian Di dan Luwen (2012), menyatakan bahwa ketika pelanggan mencari informasi dalam komunitas online, mereka akan merasa lebih berguna untuk membuat keputusan pembelian jika mereka menganggap informasi tersebut dapat dipercaya. Penelitian yang dilakukan oleh Cheung dan Thadani, (2012) bahwa kredibilitas sumber pada adopsi eWOM dapat dimediasi oleh kegunaan informasi.

$\mathrm{H}_{7}$ : Kegunaan informasi memediasi kredibilitas sumber terhadap niat pembelian

\section{METODE PENELITIAN}

Berdasarkan penjelasan sebelumnya, penelitian ini termasuk dalam penelitian deskriptif dan asosiatif yang bertujuan untuk menjelaskan pengaruh antar variabel. Kerangka konseptual yang diajukan sebagai dasar penentu hipotesis ditunjukkan pada Gambar 3.

Penelitian ini dilakukan di Kota Denpasar. Kota Denpasar memiliki akses internet tertinggi, sebanyak 68 persen masyarakatnya telah mengakses internet, selain itu Kota Denpasar merupakan Ibu Kota dari Provinsi Bali sehingga hal tersebut akan mendukung untuk dijadikan segmentasi penelitian. 


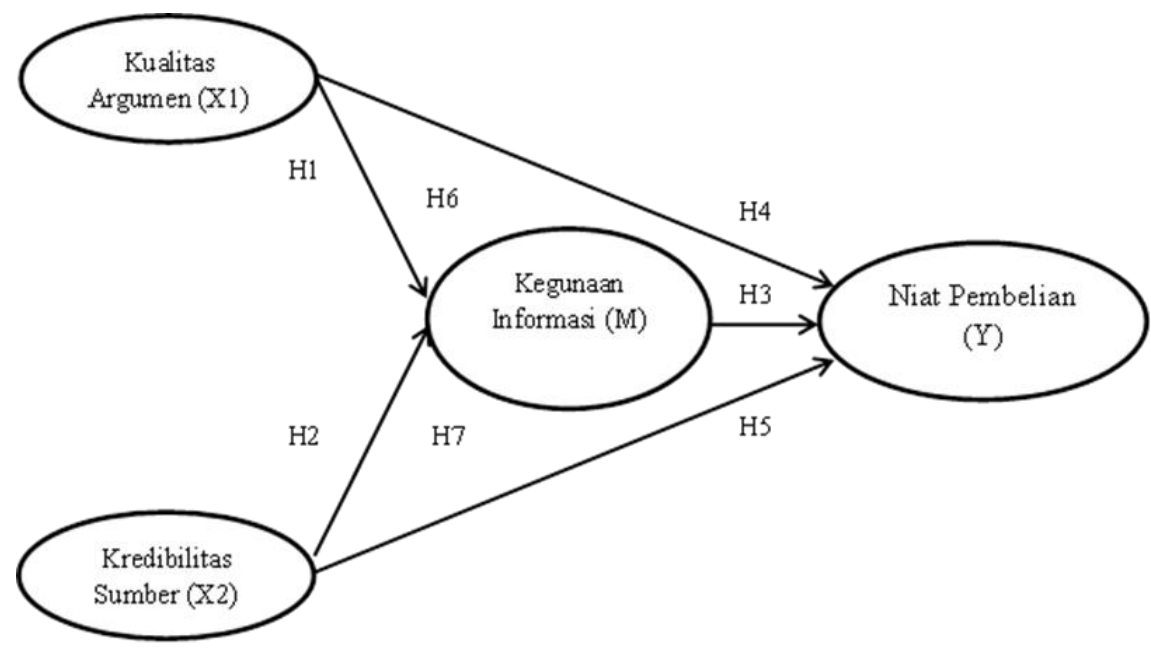

Gambar 3. Kerangka Konseptual Penelitian

Sumber: Data Diolah, 2019

Populasi dari penelitian adalah seluruh masyarakat Kota Denpasar yang belum pernah membeli lipstick Wardah, dengan demikian jumlah populasi yang digunakan adalah infinite. Penelitian ini menggunakan 10 indikator ukuran sampelnya berkisar pada rentang 50-100 responden dengan purposive sampling sebagai teknik pengambilan sampel. Sehingga ukuran sampel penelitian yang digunakan sebanyak 100 responden. Kuesioner digunakan sebagai instrumen dalam pengumpulan data, maka diperlukan pengujian validitas dan realibilitas agar kuesioner layak dan dapat digunakan sebagai sumber data yang valid. Masing-masing variabel penelitian dijabarkan melalui indikator pada Tabel 3.

Tabel 3.

\section{Indikator Penelitian}

\begin{tabular}{|c|c|c|}
\hline Variabel & Indikator & Sumber \\
\hline \multirow{3}{*}{ Kualitas Argumen } & 1. Relevansi & \multirow{3}{*}{ Cheung dan Thadani (2012) } \\
\hline & 2. Aktualitas & \\
\hline & $\begin{array}{ll}\text { 3. } & \text { Keakuratan } \\
4 & \text { Kelengkapan }\end{array}$ & \\
\hline & 1. Keahlian & \\
\hline Kredibilitas Sumber & 2. Kepercayaan & Cheung et al. (2008) \\
\hline Kegunaan Informasi & $\begin{array}{l}\text { 1. Bernilai } \\
\text { 2. Informatif }\end{array}$ & Sussman dan Siegal (2003) \\
\hline Niat Pembelian & $\begin{array}{l}\text { 1. Kepastian Untuk Memilih } \\
\text { 2. Kepastian Untuk Membeli }\end{array}$ & Orth et al. (2007) \\
\hline
\end{tabular}

Sumber: Data diolah, 2019

Penelitian ini menggunakan dua jenis data yaitu, data kualitatif dan data kuantitatif. Data kuantitatif dalam penelitian ini adalah data pengguna internet di Indonesia pada tahun 2017 dan 2018 (APJII), statista.com mengenai jumlah tampilan konten kecantikan di YouTube tahun 2006-2018 dan top brand index mengenai data produk lipstick pada tahun 2015 sampai dengan 2019. Sementara 
data kualitatif dalam penelitian ini adalah berupa jawaban yang diberikan responden dalam kuesioner.

Dalam penelitian ini teknik analisis yang digunakan adalah teknik analisis jalur (path analysis). Riduwan dan Kuncoro (2017:116) menyatakan analisis jalur digunakan untuk menjelaskan besarnya pengaruh variabel eksogen terhadap variabel lain yang diberlakukan sebagai variabel endogen. Uji asumsi klasik juga digunakan dalam penelitian ini yang terdiri dari uji normalitas, uji multikolinieritas dan uji heteroskedastisitas.

Pengujian hipotesis mediasi dilakukan dengan prosedur Uji Sobel. Uji Sobel digunakan untuk menguji kekuatan pengaruh tidak langsung variabel kegunaan informasi $(\mathrm{M})$ memediasi kualitas argumen $\left(\mathrm{X}_{1}\right)$ dan kredibilitas sumber $\left(\mathrm{X}_{2}\right)$ terhadap niat pembelian (Y), dengan cara mengalihkan koefisien jalur $\mathrm{X}$ terhadap M (a) dengan koefisien jalur M terhadap Y (b) atau ab.

\section{HASIL DAN PEMBAHASAN}

Uji validitas bertujuan untuk menunjukkan sebuah instrumen dikatakan memiliki validitas apabila instrumen tersebut mampu menunjukkan sejauh mana suatu alat ukur mengukur apa yang ingin diukur (Rahyuda, 2017:205). Hasil uji validitas instrumen penelitian yang disajikan dalam Tabel 4. menunjukkan bahwa seluruh indikator pernyataan dalam variabel kualitas argumen, kredibilitas sumber, kegunaan informasi, dan niat pembelian memiliki pearson correlation lebih besar dari 0,30 sehingga seluruh indikator tersebut telah memenuhi syarat validitas data.

Tabel 4.

Hasil Uji Validitas

\begin{tabular}{|c|c|c|c|c|}
\hline Variabel & Indikator Penelitian & Instrumen & $\begin{array}{l}\text { Pearson } \\
\text { Correlation }\end{array}$ & Keterangan \\
\hline \multirow{6}{*}{$\begin{array}{l}\text { Kualitas Argumen } \\
\text { (X1) }\end{array}$} & \multirow[t]{2}{*}{ Relevansi } & $\mathrm{X}_{1.1 .1}$ & 0.881 & Valid \\
\hline & & $\mathrm{X}_{1.1 .2}$ & 0.861 & Valid \\
\hline & \multirow[t]{2}{*}{ Aktualitas } & $\mathrm{X}_{1.2 .1}$ & 0.931 & Valid \\
\hline & & $\mathrm{X}_{1.2 .2}$ & 0.928 & Valid \\
\hline & Keakuratan & $\mathrm{X}_{1.3}$ & 0.931 & Valid \\
\hline & Kelengkapan & $\mathrm{X}_{1.4}$ & 0.893 & Valid \\
\hline \multirow{3}{*}{$\begin{array}{l}\text { Kredibilitas Sumber } \\
\text { (X2) }\end{array}$} & Keahlian & $\mathrm{X}_{2.1}$ & 0.916 & Valid \\
\hline & \multirow[t]{2}{*}{ Kepercayaan } & $\mathrm{X}_{2.2 .1}$ & 0.923 & Valid \\
\hline & & $\mathrm{X}_{2.2 .2}$ & 0.900 & Valid \\
\hline Kegunaan & Bernilai & M.1 & 0.876 & Valid \\
\hline Informasi (M) & Informatif & $\mathrm{M}_{2}$ & 0.854 & Valid \\
\hline \multirow[t]{2}{*}{ Niat Pembelian (Y) } & Kepastian untuk Memilih & $\mathrm{Y}_{.1}$ & 0.916 & Valid \\
\hline & Kepastian untuk Membeli & $\mathrm{Y}_{.2}$ & 0.942 & Valid \\
\hline
\end{tabular}

Sumber: Data Diolah, 2019

Uji reliabilitas bertujuan untuk menunjukkan sejauh mana suatu alat pengukur dapat dipercaya atau dapat diandalkan, dengan kata lain menunjukkan konsistensi suatu alat pengukur di dalam mengukur gejala yang sama (Rahyuda, 2017:209). 
Tabel 5.

Hasil Uji Reliabilitas

\begin{tabular}{lll}
\hline Variabel & Cronbach's Alpha & Keterangan \\
\hline Kualitas Argumen & 0.922 & Reliabel \\
Kredibilitas Sumber & 0.801 & Reliabel \\
Kegunaan Informasi & 0.912 & Reliabel \\
Niat Pembelian & 0.835 & Reliabel \\
\hline Sumber: Data & &
\end{tabular}

Sumber: Data diolah, 2019

Tabel 5. menunjukkan bahwa keempat instrumen penelitian yaitu variabel kualitas argumen, kredibilitas sumber, kegunaan informasi dan niat pembelian memiliki koefisien Cronbach's Alpha lebih besar dari 70 sehingga pernyataan pada kuesioner tersebut reliabel.

Penelitian ini menggunakan teknik analisis jalur (path analysis). Model ini bertujuan untuk mempertimbangkan bahwa dalam suatu penelitian apabila hubungan yang dianalisis merupakan hubungan sebab akibat dengan model yang kompleks (Utama, 2016:159). Hasil dari pengolahan data untuk persamaan regresi satu disajikan dalam Tabel 6. sebagai berikut.

Tabel 6.

Hasil Analisis Jalur Persamaan Regresi 1

\begin{tabular}{|c|c|c|c|c|c|c|}
\hline \multirow[t]{2}{*}{ Model } & & \multicolumn{2}{|c|}{$\begin{array}{l}\text { Unstandardized } \\
\text { Coefficients }\end{array}$} & \multirow{2}{*}{$\begin{array}{c}\text { Standardized } \\
\text { Coefficients } \\
\text { Beta } \\
\end{array}$} & \multirow[t]{2}{*}{$\mathbf{T}$} & \multirow[t]{2}{*}{ Sig. } \\
\hline & & B & Std.Error & & & \\
\hline 1 & (Constant) & 0.184 & 0.209 & & 0.883 & 0.380 \\
\hline & Kualitas Argumen & 0.696 & 0.081 & 0.663 & 8.560 & 0.000 \\
\hline & Kredibilitas Sumber & 0.279 & 0.083 & 0.260 & 3.358 & 0.001 \\
\hline $\mathrm{R} 1^{2}$ & $: 0.780$ & & & & & \\
\hline F statistil & $: 171.940$ & & & & & \\
\hline Sig. F & $: 0.000$ & & & & & \\
\hline
\end{tabular}

Berdasarkan data yang disajikan pada Tabel 6., maka persamaan strukturalnya dapat disusun sebagai berikut.

$$
\begin{aligned}
& M=\beta_{1} X_{1}+\beta_{2} X_{2}+\varepsilon_{1} \ldots \ldots \ldots \ldots . \\
& M=0,663 X_{1}+0,260 X_{2}+\varepsilon_{1}
\end{aligned}
$$

Nilai $\beta_{1}$ adalah sebesar 0,663 memiliki arti kualitas argumen berpengaruh positif terhadap kegunaan informasi, dengan kata lain jika faktor kualitas argumen meningkat maka kegunaan informasi akan meningkat.

Nilai $\beta_{2}$ adalah sebesar 0,260 memiliki arti kredibilitas sumber berpengaruh positif terhadap kegunaan informasi, dengan kata lain jika faktor kredibilitas sumber meningkat maka kegunaan informasi akan meningkat. Hasil pengolahan data untuk persamaan regresi 2 disajikan dalam Tabel 7.

Berdasarkan data yang disajikan pada Tabel 7., maka persamaan strukturalnya dapat disusun sebagai berikut.

$$
\begin{aligned}
& Y=\beta_{3} M+\beta_{4} X_{1}+\beta_{5} X_{2}+\varepsilon_{2} \ldots \ldots \ldots \ldots \ldots . . . . . . . . . .258 X_{2}+\varepsilon_{2}
\end{aligned}
$$


Tabel 7.

Hasil Analisis Jalur Persamaan Regresi 2

\begin{tabular}{|c|c|c|c|c|c|c|}
\hline \multirow[t]{2}{*}{ Model } & & \multicolumn{2}{|c|}{$\begin{array}{l}\text { Unstandardized } \\
\text { Coefficients }\end{array}$} & \multirow{2}{*}{$\begin{array}{c}\text { Standardized } \\
\text { Coefficients } \\
\text { Beta }\end{array}$} & \multirow[t]{2}{*}{$\mathbf{T}$} & \multirow[t]{2}{*}{ Sig. } \\
\hline & & B & Std.Error & & & \\
\hline \multirow[t]{5}{*}{1} & (Constant) & 0.198 & 0.236 & & 0.838 & 0.404 \\
\hline & Kualitas Argumen & 0.325 & 0.122 & 0.307 & 2.674 & 0.009 \\
\hline & Kredibilitas Sumber & 0.278 & 0.099 & 0.258 & 2.809 & 0.006 \\
\hline & Kegunaan & 0.347 & 0.115 & 0.344 & 3.030 & 0.003 \\
\hline & Informasi & & & & & \\
\hline $\mathrm{R} 2^{2}$ & $: 0.727$ & & & & & \\
\hline F statistil & $: 85.241$ & & & & & \\
\hline Sig. F & $: 0.000$ & & & & & \\
\hline
\end{tabular}

Nilai $\beta_{3}$ adalah sebesar 0,344 memiliki arti kegunaan informasi berpengaruh positif terhadap niat pembelian, dengan kata lain jika kegunaan informasi meningkat maka niat pembelian akan meningkat.

Nilai $\beta_{4}$ adalah sebesar 0,307 memiliki arti kualitas argumen berpengaruh positif terhadap niat pembelian, dengan kata lain jika kualitas argumen meningkat maka niat pembelian akan meningkat.

Nilai $\beta_{5}$ adalah sebesar 0,258 memiliki arti kredibilitas sumber berpengaruh positif terhadap niat pembelian, dengan kata lain jika kredibilitas sumber meningkat maka niat pembelian akan meningkat.

Berdasarkan persamaan regresi 1 dan 2 , diketahui nilai dari $\mathrm{R} 1^{2}=0,780$ dan $\mathrm{R} 2^{2}=0,727$ maka nilai error untuk masing-masing persamaan dihitung sebagai berikut.

$$
\begin{aligned}
& \mathrm{e}=\sqrt{1-R^{2}} \ldots \ldots \ldots \ldots \ldots \ldots \ldots \ldots \ldots \ldots \ldots \ldots \ldots \ldots \ldots \ldots \\
& \mathrm{e}_{1}=\sqrt{1-R 1^{2}}=\sqrt{1-0,780}=0,469 \\
& \mathrm{e}_{2}=\sqrt{1-R 2^{2}}=\sqrt{1-0,727}=0,522
\end{aligned}
$$

Berdasarkan perhitungan tersebut, diketahui besarnya pengaruh $\mathrm{e}_{1}=0.469$ dan nilai dari $\mathrm{e}_{2}=0.522$. Dari nilai $\mathrm{e}_{1}$ dan $\mathrm{e}_{2}$ yang telah diketahui maka koefisien determinasi total dapat dihitung sebagai berikut.

$$
\begin{aligned}
\mathrm{R}^{2} \mathrm{~m} & =1-\left(\mathrm{Pe}_{1}\right)^{2}\left(\mathrm{Pe}_{2}\right)^{2} \ldots \ldots \ldots . . \\
& =1-(0,469)^{2}(0,522)^{2} \\
& =1-(0,219)(0,272) \\
& =1-0,059 \\
& =0,941
\end{aligned}
$$

Koefisien determinasi total sebesar 0,941 artinya sebesar 94,1 persen variasi variabel niat pembelian dipengaruhi oleh variabel kualitas argumen, kredibilitas sumber dan kegunaan informasi, sedangkan sisanya sebesar 5,9 persen dijelaskan oleh faktor lain yang tidak dimasukkan ke dalam model. Hasil koefisien jalur pada hipotesis peneitian dapat digambarkan pada Gambar 4. berikut. 


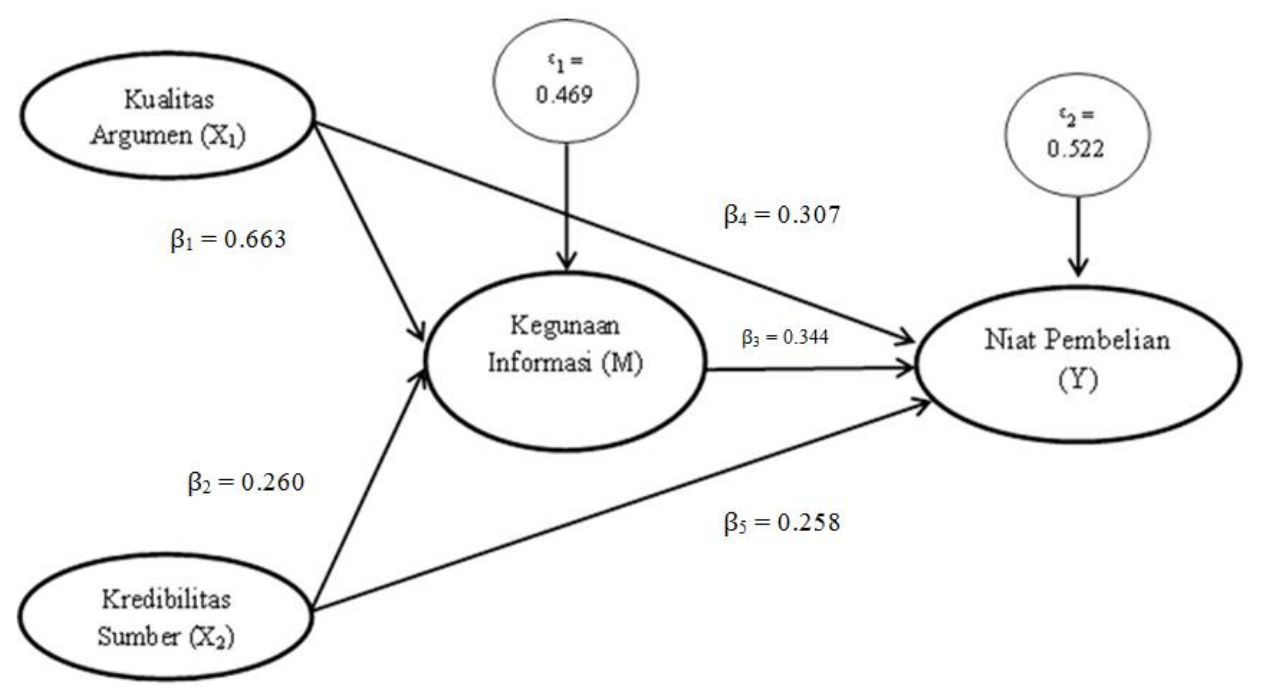

\section{Gambar 4. Diagram Model Analisis Jalur \\ Sumber: Data Diolah, 2019}

Diagram jalur telah digambarkan pada Gambar 4 maka dapat dihitung besarnya pengaruh langsung, pengaruh tidak langsung dan pengaruh total antar variabel. Perhitungan pengaruh antar variabel ditunjukkan pada Tabel 8, data tersebut menunjukkan bahwa kegunaan informasi dapat memediasi hubungan kualitas argumen dan kredibilitas sumber terhadap niat pembelian secara parsial.

Tabel 8.

Pengaruh Langsung, Pengaruh Tidak Langsung dan Pengaruh Total Kualitas Argumen $\left(\mathbf{X}_{1}\right)$, Kredibilitas Sumber $\left(\mathbf{X}_{2}\right)$, Kegunaan Informasi $(M)$ dan Niat Pembelian (Y)

\begin{tabular}{llll}
\hline $\begin{array}{l}\text { Pengaruh } \\
\text { Variabel }\end{array}$ & $\begin{array}{l}\text { Pengaruh } \\
\text { Langsung }\end{array}$ & $\begin{array}{l}\text { Pengaruh Tidak Langsung Melalui } \\
\text { Kegunaan Informasi }\end{array}$ & $\begin{array}{l}\text { Pengaruh } \\
\text { Total }\end{array}$ \\
\hline $\mathrm{X} 1 \rightarrow \mathrm{M}$ & 0.663 & - & 0.663 \\
$\mathrm{X} 2 \rightarrow \mathrm{M}$ & 0.260 & - & 0.260 \\
$\mathrm{M} \rightarrow \mathrm{Y}$ & 0.344 & - & 0.344 \\
$\mathrm{X} 1 \rightarrow \mathrm{Y}$ & 0.307 & 0.228 & 0.535 \\
$\mathrm{X} 2 \rightarrow \mathrm{Y}$ & 0.258 & 0.089 & 0.347 \\
\hline \multicolumn{2}{l}{ Sumber: Data diolah, 2019} & &
\end{tabular}

Uji sobel yang digunakan untuk menguji kekuatan pengaruh tidak langsung yaitu variabel eksogen dengan variabel endogen yang dimediasi oleh variabel mediator. Nilai koefisien z jika lebih besar dari 1,96, maka variabel kegunaan informasi dalam penelitian ini dinilai secara signifikan mampu memediasi hubungan pengaruh kualitas argumen dan kredibilitas sumber terhadap niat pembelian.

Hasil uji sobel yang telah dihitung menunjukkan bahwa nilai koefisien $\mathrm{z}$ adalah 2,8312 dan 2,1950>1,96 dengan tingkat signifikasi 0,0047 dan 0,0284< 0,05, sehingga $\mathrm{H}_{0}$ ditolak dan $\mathrm{H}_{1}$ diterima. Hasil tersebut berarti bahwa kegunaan informasi sebagai variabel mediasi dinilai secara positif dan signifikan mampu 
memediasi pengaruh kualitas argumen dan kredibilitas sumber terhadap niat pembelian.

Tabel 9.

Hasil Uji Sobel

\begin{tabular}{lll}
\hline Sobel & Nilai & Keterangan \\
\hline Z & 2,8312 & Mediasi \\
Sig & 0,0047 & Signifikan \\
\hline Sumber
\end{tabular}

Sumber: Data diolah, 2019

Tabel 10.

Hasil Uji Sobel

\begin{tabular}{lll}
\hline Sobel & Nilai & Keterangan \\
\hline $\mathrm{Z}$ & 2,1950 & Mediasi \\
Sig & 0,0284 & Signifikan \\
\hline Sumber: Data diolah, 2019 & &
\end{tabular}

Uji normalitas bertujuan untuk menguji apakah dalam residual dari model regresi yang dibuat berdistribusi normal ataukah tidak (Utama, 2016:99). Berdasarkan Tabel 11. dan Tabel 12. maka dapat dilihat bahwa nilai Kolmogorov Smirnov $(K-S)$ sebesar 0,094 dan 0,135. Hasil tersebut mengindikasikan bahwa model persamaan regresi tersebut berdistribusi normal.

Tabel 11.

Hasil Uji Normalitas Persamaan Regresi 1

\begin{tabular}{cc}
\hline & Unstandardized Residual \\
\hline $\mathrm{N}$ & 100 \\
Kolmogorov Smirnov & 1.237 \\
Asymp. Sig. (2-tailed) & 0.094 \\
\hline
\end{tabular}

Sumber: Data diolah, 2019

Tabel 12.

Hasil Uji Normalitas Persamaan Regresi 2

\begin{tabular}{cc}
\hline & Unstandardized Residual \\
\hline $\mathrm{N}$ & 100 \\
Kolmogorov Smirnov & 1.161 \\
Asymp. Sig. (2-tailed) & 0.135 \\
\hline
\end{tabular}

Sumber: Data diolah, 2019

Uji multikolinieritas bertujuan untuk menguji apakah pada model regresi ditemukan adanya korelasi antar variabel bebas. Adanya multikolinieritas dapat dilihat dari nilai tolerance atau variance inflaction factor (VIF). Jika nilai tolerance lebih dari 10 persen atau VIF kurang dari 10, maka dapat dikatakan tidak ada multikolinieritas. Berdasarkan Tabel 13. dan Tabel 14. dapat dilihat nilai tolerance untuk setiap variabel lebih besar dari 10 persen dan nilai VIF lebih kecil dari 10. Hasil tersebut mengindikasikan bahwa model persamaan regresi tersebut bebas dari multikolinieritas. 
Tabel 13.

Hasil Uji Multikolinieritas Persamaan Regresi 1

\begin{tabular}{lcc}
\hline \multicolumn{1}{c}{ Variabel } & Tolerance & VIF \\
\hline Kualitas Argumen & 0,378 & 2,647 \\
Kredibilitas Sumber & 0,378 & 2,647 \\
\hline
\end{tabular}

Sumber: Data diolah, 2019

Tabel 14.

Hasil Uji Multikolinieritas Persamaan Regresi 2

\begin{tabular}{lcc}
\hline \multicolumn{1}{c}{ Variabel } & Tolerance & VIF \\
\hline Kualitas Argumen & 0,215 & 4,647 \\
Kredibilitas Sumber & 0,338 & 2,955 \\
Kegunaan Informasi & 0,220 & 4,545 \\
\hline Sumber: Data diolah, 2019 & &
\end{tabular}

Uji heteroskedastisitas bertujuan untuk mengetahui apakah dalam model regresi terjadi ketidaksamaan varians dari residual satu pengamatan ke pengamatan yang lain. Uji heteroskedastisitas ini menggunakan uji Glejser. Jika tidak ada satu pun variabel bebas yang berpengaruh signifikan terhadap nilai absolut residual atau nilai signifikansinya di atas atau 0,05 maka tidak mengandung gejala heteroskedastisitas.

Tabel 15.

Hasil Uji Heteroskedastisitas Persamaan Regresi 1

\begin{tabular}{|c|c|c|c|c|c|c|}
\hline \multirow[t]{2}{*}{ Model } & & \multicolumn{2}{|c|}{$\begin{array}{l}\text { Unstandardized } \\
\text { Coefficients }\end{array}$} & \multirow{2}{*}{$\begin{array}{c}\begin{array}{c}\text { Standardized } \\
\text { Coefficients }\end{array} \\
\text { Beta } \\
\end{array}$} & \multirow[t]{2}{*}{$\mathbf{T}$} & \multirow[t]{2}{*}{ Sig. } \\
\hline & & B & Std.Error & & & \\
\hline \multirow[t]{3}{*}{1} & (Constant) & 0.581 & 0.135 & & 4,310 & 0.000 \\
\hline & Kualitas Argumen & -0.071 & 0.053 & -0.219 & $-1,359$ & 0.117 \\
\hline & Kredibilitas Sumber & -0.001 & 0.054 & -0.003 & -0.012 & 0.987 \\
\hline
\end{tabular}

Sumber: Data diolah, 2019

Tabel 16.

Hasil Uji Heteroskedastisitas Persamaan Regresi 2

\begin{tabular}{llccccc}
\hline \multirow{2}{*}{ Model } & & \multicolumn{2}{c}{$\begin{array}{c}\text { Unstandardized } \\
\text { Coefficients } \\
\text { B }\end{array}$} & $\begin{array}{c}\text { Standardized } \\
\text { Coefficients } \\
\text { Beta }\end{array}$ & T & Sig. \\
\hline 1 & (Constant) & 0.365 & 0.162 & & 2,253 & 0.027 \\
& Kualitas Argumen & -0.124 & 0.083 & -0.321 & $-1,491$ & 0.139 \\
& Kredibilitas Sumber & 0.116 & 0.068 & 0.292 & 1,700 & 0.092 \\
& Kegunaan & -0.001 & 0.079 & -0.003 & $-0,013$ & 0.990 \\
& Informasi & & & & &
\end{tabular}

a. Dependent Variabel : Absres2

Sumber: Data diolah, 2019

Berdasarkan Tabel 15. dapat dilihat bahwa nilai signifikansi dari variabel kualitas argumen dan kredibilitas sumber sebesar 0,117 dan 0,987 lebih besar dari 
0,05 yang berarti model yang dibuat tidak mengandung gejala heteroskedastisitas. Pada Tabel 16., dapat dilihat bahwa nilai signifikansi dari variabel kualitas argumen, kredibilitas sumber dan kegunaan informasi sebesar 0,139, 0,092 dan 0,990 lebih besar dari 0,05 yang berarti model yang dibuat tidak mengandung gejala heteroskedastisitas.

Pengaruh antara kualitas argumen terhadap kegunaan informasi dalam penelitian ini diperoleh nilai koefisien $\beta_{1}$ sebesar 0,663 dengan tingkat signifikansi $0,000 \leq 0,05$ sehingga $\mathrm{H}_{1}$ diterima dan $\mathrm{H}_{0}$ ditolak, yang mengindikasikan bahwa kualitas argumen berpengaruh positif dan signifikan terhadap kegunaan informasi. Hal ini berarti, semakin tinggi kualitas argumen dalam sebuah review maka akan semakin berguna informasi yang dirasakan oleh calon konsumen lipstick Wardah. Hasil penelitian ini sejalan dengan penelitian sebelumnya yang dilakukan oleh Chen et al. (2014), Retnowati (2017), Erkan dan Evans (2016), dan Cheng dan Ho (2015) yang menyatakan bahwa kualitas argumen berpengaruh positif dan signifikan terhadap kegunaan informasi.

Pengaruh antara kredibilitas sumber terhadap kegunaan informasi dalam penelitian ini diperoleh nilai koefisien $\beta_{2}$ sebesar 0,260 dengan tingkat signifikansi $0,001 \leq 0,05$ sehingga $\mathrm{H}_{1}$ diterima dan $\mathrm{H}_{0}$ ditolak, yang mengindikasikan bahwa kredibilitas sumber berpengaruh positif dan signifikan terhadap kegunaan informasi. Hal ini berarti, semakin kredibel sumber dalam sebuah review maka akan semakin berguna informasi yang dirasakan oleh calon konsumen lipstick Wardah, karena calon konsumen merasa percaya dan yakin akan informasi yang disampaikan oleh endorser. Hasil penelitian ini sejalan dengan penelitian sebelumnya yang dilakukan oleh Gunawan dan Huarng (2015), Soenarno dkk. (2015), Yuniarti (2019), dan Chen et al. (2014) yang menyatakan bahwa kredibilitas sumber berpengaruh positif dan signifikan terhadap kegunaan informasi.

Pengaruh antara kegunaan informasi terhadap niat pembelian dalam penelitian ini diperoleh nilai koefisien $\beta_{3}$ sebesar 0,344 dengan tingkat signifikansi $0,003 \leq 0,05$ sehingga $\mathrm{H}_{1}$ diterima dan $\mathrm{H} 0$ ditolak, yang mengindikasikan bahwa kegunaan informasi berpengaruh positif dan signifikan terhadap niat pembelian. Hal ini berarti, semakin berguna informasi yang disampaikan maka akan semakin tinggi niat pembelian yang dirasakan oleh calon konsumen lipstick Wardah. Hasil penelitian ini sejalan dengan penelitian sebelumnya yang dilakukan oleh Cheung (2014), Cho dan Sagynov (2015), dan Jap dkk. (2018) yang menyatakan bahwa kegunaan informasi berpengaruh positif dan signifikan terhadap niat pembelian.

Pengaruh antara kualitas argumen terhadap niat pembelian dalam penelitian ini diperoleh nilai koefisien $\beta_{4}$ sebesar 0,307 dengan tingkat signifikansi $0,009 \leq$ 0,05 sehingga $\mathrm{H}_{1}$ diterima dan $\mathrm{H}_{0}$ ditolak, yang mengindikasikan bahwa kualitas argumen berpengaruh positif dan signifikan terhadap niat pembelian. Hal ini berarti, semakin tinggi kualitas argumen dalam review lipstick Wardah dalam platform YouTube maka akan semakin tinggi niat pembelian dari calon konsumen yang menonton review. Hasil penelitian ini sejalan dengan penelitian sebelumnya yang dilakukan oleh Park et al. (2007), Lim et al. (2016), Ardana dan Rastini 
(2018), dan Sa'ait et al. (2016) yang menyatakan bahwa kualitas argumen berpengaruh positif dan signifikan terhadap niat pembelian.

Pengaruh antara kredibilitas sumber terhadap niat pembelian dalam penelitian ini diperoleh nilai koefisien $\beta_{5}$ sebesar 0,258 dengan tingkat signifikansi $0,006 \leq 0,05$ sehingga $\mathrm{H}_{1}$ diterima dan $\mathrm{H}_{0}$ ditolak, yang mengindikasikan bahwa kredibilitas sumber berpengaruh positif dan signifikan terhadap niat pembelian. Hal ini berarti, semakin kredibel sumber dalam review lipstick Wardah dalam platform YouTube maka akan semakin tinggi niat pembelian dari calon konsumen yang menonton review. Hasil penelitian ini sejalan dengan penelitian sebelumnya yang dilakukan oleh Arsinta dan Purnami (2015), Husna dan Bayu (2018), Larasati dan Kerti (2018), dan Safitri dan Andriani (2018) yang menyatakan bahwa kredibilitas sumber berpengaruh positif dan signifikan terhadap niat pembelian.

Hasil uji pengaruh langsung variabel kualitas argumen terhadap niat pembelian bernilai 0,307 , kemudian setelah adanya kegunaan informasi sebagai variabel mediasi, nilai pada pengaruh kualitas argumen terhadap niat pembelian meningkat menjadi sebesar 0,535. Hasil tersebut menunjukkan bahwa kegunaan informasi memediasi hubungan kualitas argumen terhadap niat pembelian secara parsial. Nilai uji sobel pengaruh kualitas argumen terhadap niat pembelian melalui kegunaan informasi adalah sebesar $\mathrm{z}=2,8312>1,96$ dan tingkat signifikansi $0,0047<0,05$. Nilai uji sobel tersebut menunjukkan bahwa kegunaan informasi mampu memediasi pengaruh kualitas argumen terhadap niat pembelian secara positif dan signifikan. Hasil penelitian ini sejalan dengan hipotesis yang dipaparkan oleh Cheung dan Thadani (2012) dan Jap dkk. (2018) yang menyatakan bahwa kegunaan informasi dapat memediasi kualitas argumen terhadap niat pembelian.

Hasil uji pengaruh langsung variabel kredibilitas sumber terhadap niat pembelian bernilai 0,258 , kemudian setelah adanya kegunaan informasi sebagai variabel mediasi, nilai pada pengaruh kredibilitas sumber terhadap niat pembelian meningkat menjadi sebesar 0,347. Hasil tersebut menunjukkan bahwa kegunaan informasi memediasi hubungan kredibilitas sumber terhadap niat pembelian secara parsial. Nilai uji sobel pengaruh kredibilitas sumber terhadap niat pembelian melalui kegunaan informasi adalah sebesar $\mathrm{z}=2,1950>1,96$ dan tingkat signifikansi $0,0284<0,05$. Nilai uji sobel tersebut menunjukkan bahwa kegunaan informasi mampu memediasi pengaruh kredibilitas sumber terhadap niat pembelian secara positif dan signifikan. Hasil penelitian ini sejalan dengan hipotesis yang dipaparkan oleh Di dan Luwen (2012), dan Cheung dan Thadani (2012) yang menyatakan bahwa kegunaan informasi dapat memediasi kredibilitas sumber terhadap niat pembelian.

\section{SIMPULAN}

Berdasarkan hasil analisis penelitian dan hasil pembahasan maka simpulan dari penelitian ini adalah Kualitas argumen berpengaruh positif dan signifikan terhadap kegunaan informasi, hasil ini berarti bahwa semakin tinggi kualitas konten dalam review lipstick Wardah maka akan semakin berguna informasi yang 
didapat oleh calon konsumen. Kredibilitas sumber berpengaruh positif dan signifikan terhadap kegunaan informasi, hasil ini berarti bahwa semakin kredibel sumber dalam review lipstick Wardah maka akan semakin berguna informasi yang didapat oleh calon konsumen. Kegunaan informasi berpengaruh positif dan signifikan terhadap niat pembelian, hasil ini berarti bahwa semakin berguna informasi yang terdapat dalam review lipstick Wardah, maka akan semakin tinggi niat pembelian yang dirasakan oleh calon konsumen. Kualitas argumen berpengaruh positif dan signifikan terhadap niat pembelian, hasil ini berarti bahwa semakin tinggi kualitas konten review lipstick Wardah, maka akan semakin tinggi niat pembelian yang dirasakan oleh calon konsumen. Kredibilitas sumber berpengaruh positif dan signifikan terhadap niat pembelian, hasil ini berarti bahwa semakin kredibel sumber dalam konten review lipstick Wardah, maka akan semakin tinggi niat pembelian yang dirasakan oleh calon konsumen. Kegunaan informasi memediasi secara positif dan signifikan hubungan kualitas argumen terhadap niat pembelian, hasil analisis yang diperoleh dari kedua teknik analisis menunjukkan bahwa secara positif dan signifikan kegunaan informasi mampu memediasi hubungan kualitas argumen terhadap niat pembelian lipstick Wardah di Kota Denpasar. Kegunaan informasi memediasi secara positif dan signifikan hubungan kredibilitas sumber terhadap niat pembelian, hasil analisis yang diperoleh dari kedua teknik analisis menunjukkan bahwa secara positif dan signifikan kegunaan informasi mampu memediasi hubungan kredibilitas sumber terhadap niat pembelian lipstick Wardah di Kota Denpasar.

Saran yang dapat diberikan berdasarkan simpulan yang dipaparkan kepada perusahaan, sebagai berikut. Wardah diharapkan mampu meningkatkan kembali kualitas pesan yang ingin disampaikan kepada calon konsumen, agar pesan yang telah diungkapkan dapat menjadi pesan yang handal dan dapat digunakan oleh calon konsumen. Wardah diharapkan dapat bekerja sama dengan beauty vlogger ataupun endorser yang ahli dalam bidangnya sehingga akan meningkatkan kepercayaan calon konsumen agar membeli produk-produk Wardah. Wardah diharapkan lebih menyesuaikan kembali pesan-pesan yang ingin disampaikan agar sesuai dengan kebutuhan calon konsumen, serta memperhatikan eWOM positif dan negatif yang disampaikan oleh calon konsumen dan konsumen, agar review selanjutnya dapat memberikan manfaat bagi calon konsumen maupun konsumen Wardah. Wardah diharapkan lebih memperhatikan kualifikasi brand ambassador dan beauty vlogger Wardah, hal ini dikarenakan masyarakat lebih mempercayai ulasan yang berasal dari sumber yang sudah ahli dibandingkan ulasan dari sesama konsumen lain. Wardah diharapkan mampu untuk memberikan informasi yang sesuai kebutuhan calon konsumen dan memberikan informasi yang relevan, agar calon konsumen dapat merasakan bahwa informasi tersebut berguna sehingga akan menimbulkan niat pembelian.

\section{REFERENSI}

Almana, A.M., \& Mirza, A.A. (2013). The Impact of Electronic Word of Mouth on Consumers' Purchasing Decisions. International Journal of Computer Applications, 82(9), 23-31. https://doi.org/10.5120/14145-2286. 
Ardana, Y.A., \& Rastini, N.M. (2018). Peran Citra Merek Memediasi Pengaruh E-Wom Terhadap Minat Beli Smartphone Samsung Di Kota Denpasar. EJurnal Manajemen Universitas Udayana, 7(11), 5901-5929. https://doi.org/ 10.24843/ejmunud.2018.v07.i11.p04

Arsinta, G.A.P., \& Purnami, N.M. (2015). Peran Persepsi Nilai Dalam Memediasi Pengaruh Kredibilitas Celebrity Endorser Pada Niat Beli Produk Kosmetik Maybelline di Kota Denpasar. Jurnal Manajemen, Strategi Bisnis dan Kewirausahaan, 9(2), 123-134.

Asosiasi Penyelenggara Jasa Internet Indonesia. (2018). Penetrasi dan Profil Perilaku Pengguna Internet Indonesia. Booklet.

Bachdar, S. (2018). Mengenal Paragon, Produsen di Balik Kemahsyuran Wardah. Diunduh dari Marketeers website: https://marketeers.com/mengenalparagon-produsen-di-balik-kemahsyuran-wardah/.

Beauty Journal. (2019). Lipstik. Diunduh dari Journal Sociolla website: https://journal.sociolla.com/bjglossary/lipstik.

Chaffey, D., \& Chadwick, F.E. (2016). Digital Marketing: Strategy, Implementation and Practice, Sixth Edition. London: Pearson Education Limited.

Chen, C.W., Chen, W.C., \& Chen, W.K. (2014). Understanding The Effects of Ewom on Cosmetic Consumer Behavioral Intention. International Journal of Electronic Commerce Studies, 5(1), 97-102. https://doi.org/10.7903/ijecs. 1030

Cheng, Y.H., \& Ho, H.Y. (2015). Social Influence's Impact On Reader Perceptions Of Online Reviews. Journal of Business Research, 68(4), 883887. https://doi.org/10.1016/j.jbusres.2014.11.046

Cheung, C.M.K., Lee, M.K.O., \& Rabjohn, N. (2008). The Impact Of Electronic Word-Of-Mouth: The Adoption Of Online Opinions In Online Customer Communities. Internet Research, 18(3), 229-247. https://doi.org/ $10.1108 / 10662240810883290$

Cheung, C.M.K., \& Thadani, D.R. (2012). The Impact Of Electronic Word-OfMouth Communication: A Literature Analysis And Integrative Model. Decision Support Systems, 54(1), 461-470. https://doi.org/10.1016/j.dss .2012.06.008

Cheung, R. (2014). The Influence of Electronic Word-of-Mouth on Information Adoption in Online Customer Communities. Global Economic Review, 43(1), 42-57. https://doi.org/10.1080/1226508X.2014.884048

Cho, Y.C \& Sagynov, E. (2015). Exploring Factors That Affect Usefulness, Ease of Use, Trust, and Purchase Intention in The Online Environtment. International Journal of Management \& Information Systems, 19(1), 21-36. 
Di, C., \& Luwen, W. (2012). Factors Affecting e-WOM Adoption . Skripsi. Hong Kong Baptist University.

Erkan, I., \& Evans, C. (2016). The influence of eWOM in Social Media on Consumers' Purchase Intentions: An Extended Approach to Information Adoption. Computers in Human Behavior, 61, 47-55. https://doi.org/ 10.1016/j.chb.2016.03.003

Fan, Y.W., \& Miao, Y.F. (2012). Effect of Electronic Word-of-Mouth on Consumer Purchase Intention: the Perspective of Gender Differences. International Journal of Electronic Business Management, 10(3), 175-181.

Gunawan, D.D., \& Huarng, K.H. (2015). Viral Effects of Social Network and Media on Consumers' Purchase Intention. Journal of Business Research, 68(11), 2237-2241. https://doi.org/10.1016/j.jbusres.2015.06.004

Husna, R., \& Bayu Dirgantara, I. M. (2018). Analisis Pengaruh Electronic Word Of Mouth di Media Sosial YouTube Terhadap Minat Beli Produk Kosmetik Sariayu. Diponegoro Journal of Management, 7(3), 1-15.

Jap, F.O., Juanda, C., \& A. F. (2018). Faktor-Faktor dari E-WOM yang Mempengaruhi Minat Beli Hotel Secara Online pada Masyarakat Surabaya melalui Online Travel Agent (OTA). Jurnal Hospitality Dan Manajemen Jasa, 6(2), 286-294.

Kementerian Perindustrian Republik Indonesia. (2018). Industri Kosmetik Nasional Tumbuh 20\%. Diunduh dari Kementrian Perindustrian Republik Indonesia website: http://www.kemenperin.go.id/artikel/18957/ IndustriKosmetik-Nasional-Tumbuh-20.

Kompasiana. [Topik Pilihan] Mencermati Kota-Kota Cerdas di Indonesia. (2019). Diunduh dari Kompasiana website: https://www.kompasiana. com/kompasiana/5c419f6c6ddcae29be389912/topik-pilihan-mencermatikota-kota-cerdas-di-indonesia.

Kotler, P., Kartajaya H., \& Huan H.D. (2017). Marketing for Competitiveness: Asia yang Mendunia pada Era Konsumen Digital. Diterjemahkan oleh Indradya. Jakarta: PT Bentang Pustaka.

Kurnia, L. (2019). Penetrasi Internet di Bali Paling Tinggi. Diunduh dari Beritagar.id website: https://Beritagar.Id/Artikel/Berita/Penetrasi-Internet-DiBali-Paling-Tinggi.

Larasati, A., \& Kerti Yasa, N.N. (2018). The Effects of Argument Quality and Sources Credibility on Ewom Credibility and Online Reviews Adoption. International Journal of Management and Commerce Innovations, 5(2), 892-898. 
Li, J., \& Zhan, L. (2011). Online persuasion: How the Written Word Drives WOM (Evidence From Consumer-Generated Product Reviews). Journal of Advertising Research, 51(1), 239-257. https://doi.org/10.2501/JAR-51-1239-257

Lim, Y. J., Osman, A., Salahuddin, S.N., Romle, A. R., \& Abdullah, S. (2016). Factors Influencing Online Shopping Behavior: The Mediating Role of Purchase Intention. Procedia Economics and Finance, 35, 401-410. https://doi.org/10.1016/s2212-5671(16)00050-2

Martawilaga, A.I., \& Purwanegara, M.S. (2016). Information Acceptance of Electronic Words of Mouth (EWOM) and Purchase Intention Through Haul Videos Youtube. Journal of Business and Management, 5(5), 651-660.

Mishra, A., \& Satish, S. M. (2016). eWOM: Extant Research Review and Future Research Avenues. The Journal of Decision Makers, 41(3), 222-233. https://doi.org/10.1177/0256090916650952

Orth, U. R., Koenig, H. F., \& Firbasova, Z. (2007). Cross-National Differences in Consumer Response to the Framing of Advertising Messages: An Exploratory Comparison from Central Europe. European Journal of Marketing, 41(3-4), 327-348. https://doi.org/10.1108/03090560710728363

Paragon Innovation. (2019). Brands: Wardah. Diunduh dari PTI Paragon website: https://www.paragon-innovation.com/brands.

Park, D. H., Lee, J., \& Han, I. (2007). The Effect of On-line Consumer Reviews on Consumer Purchasing Intention: The Moderating Role of Involvement. International Journal of Electronic Commerce, 11(4), 125-148. https://doi.org/10.2753/JEC1086-4415110405

Rahyuda, K. (2017). Metode Penelitian Bisnis, Edisi Revisi 2017. Denpasar: Udayana University Press 2016.

Retnowati, N. (2017). Pengaruh E-Wom (Electronic Word of Mouth) pada Situs Social Commerce Terhadap Niat Beli Generasi X , Y dan Z. Tesis. Institut Teknologi Sepuluh Nopember.

Riduwan \& Kuncoro, E.A. (2017). Cara Menggunakan dan Mamaknai Path Analysis (Analisis Jalur). Bandung: Alfabeta.

Sa'ait, N., Kanyan, A., \& Mohamad, F.N. (2016). The Effect of E-WOM on Customer Purchase Intention. International Academic Research Journal of Social Science, 2(1), 73-80.

Safitri, R., \& Andriani, I. (2018). Pengaruh Pesan pada Instagram terhadap Minat Beli Sayur Organik. Prosiding Konferensi Nasional Komunikasi, 2(1). Malang. 
Soenarno, A.R.P., Sunaryono \& Mukhammad, K.M. (2015). Analisis Pengaruh Kualitas Informasi dan Kredibilitas Sumber Terhadap Kegunaan Informasi Dan Dampaknya pada Adopsi Informasi (Studi pada Masyarakat Pengikut Akun Twitter Resmi iKaskus). Jurnal Administrasi Bisnis (JAB), 25(2), 1-8.

Statista. (2018). Annual Beauty-Related Content Views on YouTube From 2009 to 2018 (in Billions). Diunduh dari Statista: The Statistics Portal website: https://www.statista.com/statistics/294655/youtube-monthlybeauty-content-views/.

Sussman, S.W., \& Siegal, W.S. (2003). Informational Influence in Organizations: An Integrated Approach to Knowledge Adoption. Information Systems Research, 14(1), 47-65. https://doi.org/10.1287/isre.14.1.47.14767

Top Brand Index. (2019). Kategori: Perawatan Pribadi. Diunduh dari Top Brand Award website: https://www.topbrand-award.com/top-brand-index/.

Utama, S.M. (2016). Buku Ajar Aplikasi Analisis Kuantitatif untuk Ekonomi dan Bisnis. Denpasar: CV. Sastra Utama.

Yasinta Windyastari, N., \& Sulistyawati, E. (2018). Peran Brand Image Memediasi Pengaruh Kredibilitas Celebrity Endorser Terhadap Niat Beli. EJurnal Manajemen Unud, 7(12), 6932-6960.

Yuniarti, L. (2019). Pengaruh Kualitas Argumen dan Kredibilitas Sumber terhadap Adopsi Informasi dengan Kegunaan Informasi sebagai Pemediasi pada Grup Online Unit Kegiatan Mahasiswa (UKM) Universitas Airlangga Surabaya. Tesis. Universitas Airlangga.

Zap Beauty Index. (2018). Zap Beauty Index. Diunduh dari Zap Clinic website: https://zapclinic.com/zapbeautyindex. 